\title{
Phylogenetic estimation and morphological evolution of Arundinarieae (Bambusoideae: Poaceae) based on plastome phylogenomic analysis
}

Lakshmi Attigala $^{1}$, William P. Wysocki ${ }^{2,3}$, Melvin R. Duvall ${ }^{2,4}$ and Lynn G. Clark ${ }^{1,5}$

${ }^{1}$ Department of Ecology Evolution and Organismal Biology, Iowa State University, 251 Bessey

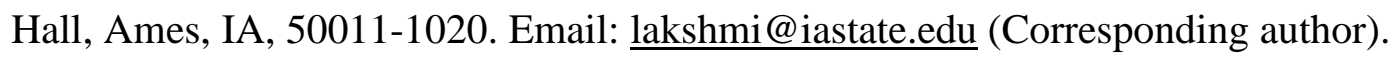

${ }^{2}$ Biological Sciences, Northern Illinois University, 1425 W Lincoln Hwy, DeKalb, IL 601152861.

${ }^{3}$ Email: wwysoc2@gmail.com.

[4Email: mel-duvall@niu.edu

${ }^{5}$ Email: 1gclark@iastate.edu 


\begin{abstract}
We explored phylogenetic relationships among the twelve lineages of the temperate woody bamboo clade (tribe Arundinarieae) based on plastid genome (plastome) sequence data. A representative sample of 28 taxa was used and maximum parsimony, maximum likelihood and Bayesian inference analyses were conducted to estimate the Arundinarieae phylogeny. All the previously recognized clades of Arundinarieae were supported, with Ampelocalamus calcareus (Clade XI) as sister to the rest of the temperate woody bamboos. Well supported sister relationships between Bergbambos tessellata (Clade I) and Thamnocalamus spathiflorus (Clade VII) and between Kuruna (Clade XII) and Chimonocalmus (Clade III) were revealed by the current study. The plastome topology was tested by taxon removal experiments and alternative hypothesis testing and the results supported the current plastome phylogeny as robust. Neighbornet analyses showed few phylogenetic signal conflicts, but suggested some potentially complex relationships among these taxa. Analyses of morphological character evolution of rhizomes and reproductive structures revealed that pachymorph rhizomes were most likely the ancestral state in Arundinarieae. In contrast leptomorph rhizomes either evolved once with reversions to the pachymorph condition or multiple times in Arundinarieae. Further, pseudospikelets evolved independently at least twice in the Arundinarieae, but the ancestral state is ambiguous.
\end{abstract}

Keywords: Alternate hypothesis testing, morphological character mapping, plastomes, pseudospikelets, rhizomes, taxon removal experiments. 


\section{Introduction}

The subfamily Bambusoideae (Poaceae) includes mainly forest grasses that comprise 115 genera and approximately 1480 species (Bamboo Phylogeny Group [BPG], 2012; Clark et al., 2015). Bambusoideae is classified into two tribes of woody bamboos (the tropical Bambuseae and the temperate Arundinarieae) and one tribe of herbaceous bamboos (the Olyreae). Their distribution includes all continents except Antarctica and Europe (BPG, 2005; Clark et al., 2015). The temperate woody bamboos (Arundinarieae) are a diverse clade of 32 genera and ca. 546 species distributed primarily in forests of the northern temperate zone in Asia, but are also found at high elevations in Old World tropical regions (Africa, Madagascar, India and Sri Lanka) (Clark et al., 2015; Soreng et al., 2015). These temperate woody bamboo species are recognized by the presence of leptomorph, monopodial rhizomes (pachymorph in some species), basipetal vegetative branch development and tetraploidy (2n=48) (BPG, 2012; Clark et al., 2015). Even though unequivocal morphological synapomorphies have yet to be identified, monophyly of the temperate woody bamboos is strongly supported in many molecular studies (BPG, 2012; Kelchner et al., 2013; Attigala et al., 2014).

Arundinarieae is well known for its complex taxonomy (Triplett et al., 2014). To date, twelve lineages (designated Clades I - XII) have been found in Arundinarieae based on analyses of both plastid and nuclear DNAs analyses, but the relationships among these clades are still not well understood or fully resolved (Triplett and Clark, 2010; Zeng et al., 2010; Yang et al., 2013; Attigala et al., 2014; Ma et al., 2014; Zhang et al., 2016). In recent years, phylogenomic analyses of plastid genomes (plastomes) have been used to resolve some of the evolutionary questions in Bambusoideae. Zhang et al. (2011) and Wu and Ge (2012) used plastome phylogenomic approaches to understand subfamily level relationships in the BOP clade and found that 
subfamilies Bambusoideae and Pooideae are sister, while another study suggested that Bambusoideae is sister to the Oryzoideae (as Ehrhartoideae) and Pooideae (Wu et al., 2009). Wu et al. (2015) and Wysocki et al. (2015) used plastome phylogenomics to examine tribal level questions in Bambusoideae and found that the plastid signal supports Arundinarieae as sister to Olyreae + Bambuseae. Burke et al. $(2012,2014)$ used this approach to examine biogeographical questions especially focusing on Arundinaria (Arundinaria applachiana, A. gigantea and A. tecta) (Clade VI of Arundinarieae) and Cryptochloa strictiflora and Olyra latifolia (Olyreae). They suggested that these New World bamboos accumulated and maintained unique plastome features over time due to biogeographic isolation. Wu et al. (2015) fully characterized the plastome of the woody bamboo Guadua angustifolia to understand plastome evolution within Neotropical-Paleotropical bamboos and found conserved gene content and evolutionary rates between Neotropical and Paleotropical woody bamboos. Further, the divergence estimates of Burke et al. $(2012,2014)$ and Wu et al. (2015) correlated with major historic climatic changes.

Zhang et al. (2016) examined the biogeographical history of Arundinarieae in detail based on six plastid DNA loci. They suggested that the Arundinarieae diversified over an estimated 12 to 14 Mya, followed by rapid radiations especially in the three most diverse lineages: Clades IV (Shibataea clade), V (Phyllostachys clade) and VI (Arundinaria clade), and that these rapid radiations were correlated with the late Miocene intensification of the East Asian monsoons. They also found no evidence that extant Sri Lankan and African temperate bamboo lineages represent early diverging lineages within the Arundinarieae.

Prior to the advent of molecular phylogenetics, traditional classification schemes for the Arundinarieae (whether recognized as a tribe or not) used a combination of reproductive (i.e., conventional spikelets vs. pseudospikelets) and rhizome morphologies (leptomorph vs. 
pachymorph) as well as stamen number to differentiate temperate woody bamboo genera and to classify them within subtribes (Keng, 1959, 1982a, 1982b, 1983a, 1983b; McClure 1966; Zhang, 1992). More recent non-molecular classifications (e.g., Soderstrom and Ellis, 1987) also incorporated anatomical or micromorphological characters. McClure (1966) used the terms "pachymorph" and "leptomorph" to differentiate the two main rhizome systems in bamboos. Typically seen in clump-forming bamboos, pachymorph rhizomes have a defined neck (short or elongated) lacking roots and axillary buds and a thick rhizome proper bearing roots and axillary buds, which curves upward and terminates in an aerial culm. In contrast, leptomorph rhizomes are characterized by long and slender axes with a single lateral bud and roots at every node, with some buds producing aerial culms. When a branch is produced, a short neck lacking buds and roots is evident. Stapleton (1997) considered only the leptomorph condition to represent "true" rhizomes, and he redefined pachymorph rhizomes as "pachymorph culm bases". Early studies suggested that pachymorph rhizomes with cespitose tillering represented the ancestral condition (Holttum, 1956, 1958; Soderstrom, 1981; Wen, 1985). In bamboos, the flower-bearing branches may have very complex structures. Of all the grasses, pseudospikelets (as typically defined) occur only in subfamily Bambusoideae (Kellogg, 2015). Conventional grass spikelets not only lack the subtending bract, prophyll and bud-bearing bracts (gemmiparous bracts) at their base, but also remain as a single unit as they mature, and all spikelets mature at more or less the same time. In contrast, each primary pseudospikelet usually develops into a tuft of pseudospikelets, with up to four or five orders of branching, as the basal buds start to produce higher order pseudospikelets.

Based on rhizome types and reproductive structures, the taxa within the currently recognized Arundinarieae were traditionally classified into three subtribes, the Arundinariinae, 
Shibataeinae and Thamnocalaminae (Zhang, 1992; BPG, 2012, Clark et al., 2015). However, several molecular studies unambiguously demonstrated the polyphyly of all three subtribes and thus caused the traditional classifications to be disregarded (Triplett and Clark, 2010; Zeng et al., 2010). Nevertheless, the evolution of these morphological characters has not been rigorously examined in a phylogenetic context, even though these are still used at the generic level in the Arundinarieae.

Although plastid sequences have been widely utilized for phylogenetic analyses, full plastome sequencing can be essential for resolving complex evolutionary relationships (Jansen et al., 2007; Parks et al., 2009; Moore et al., 2010). Further, genome-scale phylogenetic studies or plastome phylogenomics provide strong support and improved resolution compared to traditional multi-locus plastid phylogenies (Burke et al. 2014; Duvall et al. 2010; Wu and Ge 2012; Zhang et al. 2011). With the inclusion of a representative sampling of full plastomes from all 12 lineages of Arundinarieae, the current study offers a comprehensive taxonomic and plastome character sampling. The primary objectives of the current study were to (1) understand the relationships among the twelve Arundinarieae lineages based on complete plastome sequences and (2) examine the evolution of some of the taxonomically important morphological characters (i.e., rhizomes and reproductive structures).

\section{Material and methods}

\subsection{Taxon sampling and outgroup selection}

Twenty eight species were selected for phylogenomic analysis, representing all twelve lineages in the Arundinarieae. Sixteen complete plastome sequences and one partial plastome (Indocalamus sinicus) were downloaded from the NCBI GenBank data base 
(http://www.ncbi.nlm.nih.gov/genbank/) and 11 plastomes were newly generated during the current study. Two pooid grasses: Hordeum vulgare subsp. vulgare and Lolium perenne; two herbaceous bamboos: Cryptochloa strictiflora and Olyra latifolia; two Neotropical woody bamboos: Chusquea spectabilis and Olmeca reflexa; and two Paleotropical woody bamboos: Bambusa bambos and the newly sequenced Melocanna baccifera were selected as outgroups for the phylogenomic study (Table 1).

\subsection{DNA extraction, Illumina sequencing and quality control of plastome sequences}

Genomic DNA was extracted for 11 bamboo species (Bergbambos tessellata, Chimonocalamus sp., Fargesia nitida, Kuruna debilis, K. densifolia, Melocanna baccifera, Oldeania alpina, Phyllostachys aurea, Pleioblastus hindsii, Sasa veitchii, Shibataea kumasaca) from silica dried leaf tissues. A manual homogenization step in liquid nitrogen was performed followed by a DNA extraction following the Qiagen DNeasy Plant Mini Kit (Qiagen Inc., Valencia, CA) protocol provided by the manufacturer.

Initial total genomic DNA concentrations were measured using the Qubit fluorometric quantitation system (Life Technologies, Grand Island, NY, USA) and were diluted to $2.5 \mathrm{ng} / \mu \mathrm{l}$ in $20 \mu \mathrm{l}$ water. The Nextera Illumina library preparation kit (Illumina, San Diego, CA, USA) was used to prepare libraries for sequencing and the DNA Clean and Concentrator kit (Zymo Research, Irvine, CA, USA) was used for library sample purification. Sequencing was performed on a HiSeq 2000 (Illumina, San Diego, CA, USA) using single reads at the Iowa State University DNA Sequencing Facility, Ames, IA, USA. The reads generated by this method were approximately $100 \mathrm{bp}$ in length.

SolexaQA software package's DynamicTrim v2.1 (Cox et al., 2010) was used with default settings to trim lower quality nucleotides from the ends of each read and the short 
fragments $[<25 \mathrm{bp}$ in length (default setting)] were removed with LengthSort v2.1 in the same package.

\subsection{Assembly and alignment of plastomes}

A de novo method was used to assemble seven of the complete plastomes. The Velvet software package was run iteratively similar to methods described in Wysocki et al. (2014). Any remaining gaps in the plastomes were determined using contigs or reads by locating overlapping regions of at least $20 \mathrm{bp}$ until the circular map was complete with no gaps or ambiguities. Four plastomes (Kuruna debilis, K. densifolia, Melocanna baccifera, Pleioblastus hindsii) could not be fully sequenced due to low coverage. These were assembled using a reference-based method in which reads were mapped to a closely-related reference plastome, a consensus region was extracted, and ambiguous regions were manually repaired. Bambusa bambos was used as a reference plastome for the $M$. baccifera assembly and A. gigantea was used as a reference plastome for the remaining taxa. Regions that could not be assembled were scored as "N"s. Because of the presence of ambiguous regions around the IR-single copy boundaries, plastomes

from $K$. debilis, $K$. densifolia, and $P$. hindsii were banked with one IR region. However, a second inverted repeat region was estimated using the reference plastome and added to downstream analyses. The length of each ambiguous site was determined using a reference plastome. All 28 genome sequences were aligned with MAFFT V7.017 (Katoh et al., 2005). The alignments were checked manually and poorly aligned regions were adjusted manually. Nucleotide positions that contained one or more gaps introduced by the alignments were removed from the matrix and one of the inverted repeat regions was removed. 


\subsection{Plastome phylogenomic analysis of Arundinarieae}

Plastome sequences were analyzed using maximum parsimony (MP) with PAUP* $4.0 \mathrm{~b} 10$ (Swofford, 2002), maximum likelihood (ML) with RAxML version 8.0.X (Stamatakis, 2006) and Bayesian inference (BI) with MrBayes 3.2 (Huelsenbeck and Ronquist, 2001; Ronquist et al., 2003; Ronquist et al., 2011). MP analysis was performed with 1000 random addition sequences, and tree bisection-reconnection (TBR) branch swapping. A full heuristic bootstrap was conducted for MP with 1000 bootstrap replicates, each with 100 random addition sequence replicates, to assess the relative support for each node. Akaike information criterion (AIC) calculations, implemented in jModelTest 0.1 (Guindon and Gascuel, 2003; Posada, 2008), were used to select the appropriate model of sequence evolution for the plastome dataset. The general time-reversible model of DNA sequence evolution with invariant sites and gamma-distributed rate heterogeneity $(\mathrm{GTR}+\mathrm{I}+\mathrm{G})$ was among a group of equally best fit models. Hence the GTR $+\mathrm{I}+\mathrm{G}$ model was used in the ML analysis. ML analysis was conducted by rapid bootstrap (1000 replicates) analysis and searching for the best-scoring ML Tree. BI was conducted with flat priors. The Markov chain Monte-Carlo algorithm was executed for four chains of 10,000,000 generations per run, sampling every 2,000 generations, and a chain-heating temperature of 0.2 ; this entire procedure was conducted twice. Posterior probabilities (PP) were analyzed after a burn-in of 1,000,000 trees and then the remaining samples were summarized and a majority-rule consensus tree was constructed.

When assessing branch support in the resultant phylogeny, the threshold value for the bootstrap criterion for both MP and ML was 70\% and posterior probability measure for BI was 0.95 (Mason-Gamer and Kellogg 1996, Wilcox et al. 2002). Support values at each node fell into four categories: strong support, moderate support, low support and lacking support. If MPBS and 
MLBS were both above $90 \%$ and BI was 1.00 that was considered as strong support. It was considered moderate support if the MPBS and MLBS were $80 \%-89 \%$ and BI was 0.99 . If the MPBS and MLBS were 70\%-79\% and BI was $0.95-0.98$, it was considered as a low level of support. Values less than 70\% MP Bootstrap (MPBS)/ML Bootstrap (MLBS) and less than 0.95 PP were considered to be lacking support.

\subsection{Taxon removal experiments}

To test if there were any potential errors caused by long branch attraction (LBA), taxon removal experiments were performed (Kelchner et al., 2013). Especially to test if outgroup selection affected the topology of our ingroup, ML (model: GTR + I + G) analyses were conducted for each of five subset datasets that were created by removing 1) only Pooideae taxa,

2) Pooideae and Olyreae taxa, 3) Pooideae and Bambuseae taxa, 4) Bambuseae and Olyreae taxa, and 5) all outgroup taxa. The ML topology from each analysis was compared with the original plastome tree topology for changes in relationships among the remaining taxa.

\subsection{Alternate hypothesis testing}

We tested whether the plastome dataset provided sufficient evidence to reject particular hypotheses of relationships suggested by previous studies (e.g., monophyly of the Arundinaria clade plus the Phyllostachys clade, monophyly of the Kuruna clade plus Bergbambos, the sister relationship of the Kuruna clade to the rest of the temperate woody bamboo clades, etc.) (Table 2). Constraint trees were generated in MacClade 4.08 (Maddison and Maddison, 2005) by forcing test groups to be monophyletic or sister, but otherwise allowing taxa to "float," and ML analyses were performed in RAxML version 8.0.X (Stamatakis, 2006) using each constraint in turn. The Shimodaira- Hasegawa (SH) test (Shimodaira and Hasegawa, 1999) as implemented in 
RAxML version 8.0.X was then used to test the significance of differences in tree statistics among different topologies in comparison with the ML plastome data tree topology.

\subsection{Network Analysis}

As another means of visualizing the signal in the dataset and to evaluate possible phylogenetic signal conflicts, neighbor-net analysis was performed with SplitsTree4 v. 4.13.1 (Huson and Bryant, 2006) and all the outgroup taxa were excluded to better show character conflicts between ingroup taxa.

\subsection{Morphological character optimization}

A matrix of morphological character states was generated for each taxon for rhizome types and reproductive structures based on herbarium specimens (ISC, K, MO, US) and published literature (Soderstrom and Ellis, 1988; Clayton et al., 2006 onwards; Li et al., 2006; Attigala et al., 2014). The two main forms of rhizomes seen in Bambusoideae are leptomorph and pachymorph (McClure, 1966). For the purpose of character state coding, leptomorph and pachymorph rhizomes were scored as 0 and 1 respectively, without considering any tillering or neck length variation. The two main forms of reproductive structures seen in Bambusoideae are conventional spikelets and pseudospikelets. A conventional grass spikelet bears two empty proximal glumes and one to many distal florets. However, pseudospikelets are complex structures typically consisting of a subtending bract, a prophyll, one or more gemmiparous bracts, 0 to a few empty bracts (glumes) and the spikelet proper (Judziewicz et al., 1999; Tyrrell et al., 2012). Absence of pseudospikelets (= presence of conventional spikelets) was scored as 0 while pseudospikelets lacking only subtending bracts were referred as incomplete pseudospikelets and scored as 1. Pseudospikelets with all of the requisite structures were 
considered to be complete pseudospikelets and scored as 2 (Supplementary material: Appendix). With the use of the "Trace character history" option, a simple ancestral character state reconstruction was performed with the parsimony ancestral states method in Mesquite V 2.75 (Maddison and Maddison, 2011). Both rhizome types and reproductive structures were then optimized on the phylogenetic tree topology obtained from the plastome data.

\section{Results}

\subsection{New genome assembly and alignment of plastomes}

Eleven temperate woody bamboo plastomes were newly generated during the current study. Total length and lengths of the plastome regions are reported in Table 1. Of the 11 new plastomes, seven were complete. The percentage of missing sites varied from $0.9 \%-10.2 \%$ for the newly assembled plastomes and they varied from 117,358 to 140,064 base pairs (bp) in genome size. The lengths of the large single copy (LSC) and small single copy (SSC) regions varied from 82,878 bp to 83,348 bp and 12,569 bp to 15,143 bp respectively while the inverted repeat (IR) lengths ranged from 20,026 bp to 21,831 bp for the newly generated plastomes.

The multiple sequence alignment of all 28 species (including both newly generated and previously published plastomes) after excluding one of the inverted repeat (IR) regions was $127,241 \mathrm{bp}$. Removal of alignment columns with gaps reduced the alignment length to 99,853 bp. Of the total aligned length, $87.27 \%$ of the sites were invariable; of the $12,710(12.73 \%)$ variable sites, $4,773(4.78 \%)$ were parsimony informative.

\subsection{Plastome Phylogenomic analyses}

The MP analysis resulted in a single most parsimonious tree with a length of 16,410 steps, consistency index (CI) [excluding uninformative characters] $=0.6871$ and homoplasy 
index $(\mathrm{HI})=0.1515$. The MP tree topology was mostly similar to the ML and BI tree topologies of the plastome dataset, but with a few exceptions (see below). The ML and BI tree topologies were identical to each other, but with differing support values. Fig.1 shows the phylogeny obtained from BI with all three types of support values: MP bootstrap values (MPBS), ML bootstrap values (MLBS) and the BI posterior probabilities (PP).

All three analyses strongly supported the monophyly of the Arundinarieae. The sister relationship of Arundinarieae to the rest of the Bambusoideae (Bambuseae plus Olyreae) and the sister relationship between Bambuseae and Olyreae were robustly supported with 100\% MPBS, 100\% MLBS and 1.00 PP. As seen in Fig. 1, MP, ML and BI analyses of the plastomes recovered all 12 temperate woody bamboo lineages: Bergbambos (Clade I), African alpine bamboos (Clade II), Chimonocalamus (Clade III), Shibataea clade (Clade IV), Phyllostachys clade (Clade V), Arundinaria clade (Clade VI), Thamnocalamus (Clade VII), Indocalamus wilsonii (Clade VIII), Gaoligongshania (Clade IX), Indocalamus sinicus (Clade X), Ampelocalamus calcareus (Clade XI) and Kuruna (Clade XII). Of the 16 total ingroup nodes, 10 were strongly supported (>90\% MPBS, >90\% MLBS, $1.00 \mathrm{PP}$ ) and three were moderately supported $(89 \%>$ MPBS $>80 \%, 89 \%>$ MLBS $>80 \%, 0.99$ PP $)$. A single node was moderately supported only in the ML and BI analyses and this node was not resolved in the MP analysis. Two other nodes were well supported only in the BI analysis. According to all three analyses Ampelocalamus calcareus (Clade XI) was well supported as sister to the rest of the temperate woody bamboo clades. The two nodes that grouped Clades I, II, III, V, VII, XII and Clades IV, VI, VIII were well supported only in the BI (1.00 PP) analysis. In addition, there was significant evidence to support the sister relationship of the Kuruna + Chimonocalamus clades and the 
Bergbambos + Thamnocalamus clades (100\% MPBS, 100\% MLBS, 1.00 PP) in all three analyses.

\subsection{LBA and alternative hypothesis testing}

All five taxon removal experiments performed to test for potential LBA resulted in tree topologies completely congruent to the original plastome tree topology regardless of the outgroup taxa (topologies not shown).

Results of the SH test are summarized in Table 2. Based on the SH test, our data reject the monophyly of the following: Clades V + VII (Phyllostachys + Thamnocalamus), Clades I + XII (Bergbambos + Kuruna), Clades VII + XII (Thamnocalamus + Kuruna), Clades I + II (Bergbambos + African alpine bamboos) and Clades XII + VII + I + II (Kuruna + Thamnocalamus + Bergbambos + African alpine bamboos). Our data also reject the sister relationship of the Kuruna clade (Clade XII) to the remaining Arundinarieae. Thus, all these alternative hypotheses generated were significantly less plausible $(\mathrm{p}<0.01)$ compared to the original ML tree topology.

\subsection{Network analysis}

The neighbor-net analysis recovered the twelve lineages with the exception of showing some character conflicts between the species with missing data in Clades X (Indocalamus sinicus) and XII (Kuruna) (Fig. 2). Furthermore, some character conflicts were visible between Acidosasa purpurea and Pleioblastus hindsii. Except for these two sets of character conflicts, the other relationships are tree-like and represented all the lineages in the tribe (Fig. 2).

\subsection{Morphological character mapping}


Table 3 summarizes the presence of different rhizome types and reproductive structures within Arundinarieae. Based on the morphological character mapping, pachymorph rhizomes were inferred as the ancestral condition. Pachymorph rhizomes were consistently present in Bambuseae, Olyreae and clades I, II, III, VII, IX, XI and XII of Arundinarieae (Fig. 3A). One of the two sampled members of the Phyllostachys clade (Clade V) is pachymorph (Fargesia) and one is leptomorph (Phyllostachys). All sampled members of Clades IV and VI, Indocalamus sinicus (Clade X) and Indocalamus wilsonii (Clade VIII) possess leptomorph rhizomes. With respect to reproductive structures, pseudospikelets were present in two outgroup members, namely the two representatives of the Paleotropical woody bamboos: Bambusinae (Bambusa bambos) and Melocanninae (Melocanna baccifera). Within the Arundinarieae, only Phyllostachys aurea of the Phyllostachys clade (Clade V) and Shibataea kumasaca of the Shibataea clade (Clade IV) possess pseudospikelets (Fig. 3B).

\section{Discussion}

\subsection{Plastome phylogenomics}

The newly assembled plastome sequence lengths were very similar to previously published plastid genomes of temperate woody bamboos (Zhang et al., 2011; Ma et al., 2014; Wysocki et al., 2015). The high percentage (87.27\%) of invariable sites indicates the low level of sequence variability in temperate woody bamboo plastomes.

The MP phylogeny was mostly congruent with the ML and BI phylogenies with a few exceptions (Fig. 1) and less resolved than the ML and BI analyses. Maximum support for the monophyly of the subfamily Bambusoideae and the tribes Arundinarieae, Bambuseae and Olyreae retrieved in the current study confirm the strong support for these lineages identified in 
previous studies (Kelchner et al., 2013; Ma et al., 2014; Wu at al., 2015; Wysocki et al., 2015;

Zhang et al., 2016). Notably, the current study supports the paraphyly of the woody bamboo syndrome as noted in Wysocki et al. (2015). However, the maternally inherited plastome provides only a part of the evolutionary signal (Triplett et al., 2014).

To our knowledge, this is the first study to include all 12 lineages of the Arundinarieae in a phylogenetic analysis using complete plastome sequences. This study also resolved the backbone of Arundinarieae with greater support compared to other recent studies (Ma et al., 2014; Zhang et al., 2016). Ma et al. (2014) showed evolutionary relationships within Arundinarieae based on plastome phylogenomics but included only eight of the 12 lineages for their full plastome analysis. Consistent with Ma et al. (2014) and Zhang et al. (2016), we also recovered Clade XI (Ampelocalamus calcareus) as sister to the remaining Arundinarieae. Though Ma et al. (2014) recovered unresolved or contrasting branching order among Clades IV, VI and VIII, our results showed high support from BI (but not MP or ML) for the sister relationship of Clades IV + VIII and the sister relationship of Clade VI with Clades IV + VIII. In addition, the strongly supported sister relationship between Clades III and XII (Chimonocalamus + Kuruna) and the moderately supported lineage comprising Clades III, XII, II and IX $[($ Chimonocalmus + Kuruna $)+$ African alpine bamboos + Gaoligongshania $]$ were consistent with Zhang et al. (2016).

In many previous studies the phylogenetic positions of Thamnocalamus spathiflorus (Clade VII) and Bergbambos tessellata (Clade I) were ambiguous (Triplett and Clark, 2010; Zeng et al., 2010; Attigala et al., 2014; Ma et al., 2014; Wysocki et al., 2015; Zhang et al., 2016). Triplett and Clark (2010) recovered B. tessellata as an isolated lineage within Arundinarieae, essentially as part of the larger polytomy of the sampled lineages, while $T$. spathiflorus was part 
of a polytomy within the Phyllostachys clade (Clade V). In Zeng et al. (2010) and Attigala et al. (2014), T. spathiflorus and B. tessellata were resolved in a polytomy with all the other sampled lineages of Arundinarieae. Even though the complete plastome phylogenomic analyses of Ma et al. (2014) and Wysocki et al. (2015) did not include B. tessellata, a moderate level of support was recovered for the sister relationship between T. spathiflorus and Clade V (Phyllostachys clade). However, the sampling within Arundinarieae in Wysocki et al. (2015) was not representative as they only included taxa from four of the 12 lineages (Clades IV, V, VII and VII). Further, Zhang et al. (2016) showed T. spathiflorus as sister to the clade (II + IX) + $(\mathrm{III}+\mathrm{XII})[($ African alpine bamboos + Gaoligongshania $)+($ Chimonocalamus + Kuruna $)]$ and $B$. tessellata sister to Clade X (Indocalamus sinicus). However, these relationships were very poorly supported.

To test for the possibility of misidentification, we conducted a few additional analyses to compare the Ma et al. (2014) plastome sequences of T. spathiflorus and B. tessellata to those of our study. Our T. spathiflorus and the Ma et al. (2014) T. spathiflorus plastomes were 98.9\% identical while our B. tessellata and the Ma et al. (2014) plastome were only $88.8 \%$ identical, as the B. tessellata plastome of Ma et al. (2014) was missing ca. $20.8 \%$ sequence data. We also performed an ML analysis for the current dataset that also included both T. spathiflorus and B. tessellata of Ma et al. (2014) as additional sequences. This ML phylogeny (not shown here) showed $100 \%$ MLBS support for a clade consisting of the B. tessellata of Ma et al. (2014) and our T. spathiflorus and B. tessellata. Conversely, the T. spathiflorus of Ma et al. (2014) appeared as sister to Clade V (Phyllostachys clade) with moderate support (87\% MLBS), consistent with its position in Ma et al. (2014). Further, we confirmed the identity of our vouchers of $T$. spathiflorus (LC 1319) and B. tessellata (LC 1318). Also, since the Illumina sequencing of these 
two species were performed in two different runs we are certain that the samples were not mixed up or contaminated. We also note that we used material from the same voucher for $T$. spathiflorus as was used by Triplett and Clark (2010), in which this species was resolved within Clade V based on either four- or twelve-region plastid datasets. Since T. spathiflorus has a few subspecies (T. spathiflorus subsp. aristatus, T. spathiflorus subsp. nepalensis, T. spathiflorus. subsp. occidentalis, T. spathiflorus subsp. spathiflorus) and a few varieties (T. spathiflorus var. bhutanensis, T. spathiflorus var. crassinodus, T. spathiflorus var. spathiflorus) (Stapleton, 1994), they could be easily misidentified and that could be a potential reason for these discrepancies between studies.

The well supported sister relationship between B. tessellata and T. spathiflorus in our study is consistent with the previous classification of B. tessellata as T. tessellatus, although a thorough investigation of these two genera using low-copy nuclear markers and morphological analysis, combined with careful collection and determination of the vouchers, is needed before any further taxonomic changes are proposed.

\subsection{Taxon removal experiments}

One of the most common manifestations of LBA is that distantly related outgroups have a biased attraction to long branches within the ingroups (Sullivan and Swofford, 1997; Lin et al., 2002; Graham et al., 2002; Bergsten, 2005). Thus, a common suggestion is to conduct the phylogenetic analyses both with and without outgroups to compare whether the inclusion of distantly related outgroups changes the ingroup topology. The outgroup taxon removal approach we used resulted in no changes to the ingroup tree topology of the plastome data, indicating that the plastome tree topology probably was not affected by LBA, but this was also expected due to the relatively short branches within Arundinarieae. 


\subsection{Alternative tree topologies}

The alternative hypotheses we tested were selected for various reasons. Monophyly of Clade V + Clade VII was recovered by Ma et al. (2014) with moderate support from MP and ML (88\% and $85 \%$ respectively) while BI support was high (1.00 PP) in their complete plastome phylogeny. Thus, we tested this relationship with our plastome dataset. The hypothesis that Clade XII is sister to the rest of the Arundinarieae came from a previous suggestion by Triplett and Clark (2010) that the Sri Lankan Kuruna species could be the early diverging lineage of Arundinarieae. In addition, a recent study of Arundinarieae based on five plastid markers could not reject the monophyly of Clade XII + Clade I (Attigala et al., 2014) and thus we tested it as an alternative hypothesis. Further, clade origin due to close geographical proximity was also tested, e.g., all the Sri Lankan and Indian taxa form a clade (Clade XII + Clade VII) or the African species form a clade (Clade I + Clade II). Though there are currently several clades in Arundinarieae that represent the Indian, Sri Lankan, African and Madagascan temperate woody bamboo species, traditionally these taxa were all classified in the currently recognized genus Arundinaria. Thus, we tested the alternative hypothesis of the monophyly of Clades XII + VII + $\mathrm{II}+\mathrm{I}$. The SH test rejected all the alternative hypotheses suggesting that our plastome tree topology was robust and the relationships among the lineages within Bambusoideae were better represented by the current tree topology.

\subsection{Network analysis}

The neighbor-net analyses agreed with the tree topologies. The evidence of character conflict among Acidosasa purpurea and Pleioblastus hindsii in the plastome neighbor-net analysis could be due to several possible causes such as unstable conditions generated by heteroplasmy that arose through independent mutations in the plastid genome or through 
biparental inheritance of plastomes, due to haplotype polymorphism (Wolfe and Randle, 2004) or some potential amplification, sequencing, assembling artifacts or missing data (in P. hindsii). We also postulate that the character conflict among Clades X and XII could be due to missing data.

\subsection{Morphological character evolution}

Despite the recognition of 12 lineages within the Arundinarieae, little work has been done on morphological evolution in the tribe due in large measure to the lack of resolution among these lineages in previous studies. Rhizomes and pseudospikelets are two of the least well understood morphological traits in bamboos. Few rigorous discussions of rhizome structure are available (Rivière and Rivière, 1879; McClure, 1966; Stapleton, 1997); lack of study of rhizome structure is likely due to the fact that rhizomes are almost entirely or wholly underground and very difficult to unearth due to the size of the plants. Similarly, detailed study of pseudospikelets has been limited in part due to the intermittent flowering cycles of woody bamboos and in part due to the complex nature of these structures (McClure, 1966). These two characters therefore rarely have been examined in an evolutionary context.

Of the 32 genera recognized within Arundinarieae (Kellogg 2015; Soreng et al. 2015), we sampled species from 16 (50\%) (Table 3). However, since we included only 28 of the 546 species within Arundinarieae, the species-level representation is only ca. 5\%. Within the two largest clades, the Phyllostachys clade (Clade V) and the Arundinaria clade (Clade VI), the presence of leptomorph rhizomes as a percentage of the genera is 50\% and $100 \%$ while at the species level it is $36 \%$ and $100 \%$ respectively. Clades IV, VIII and X are $100 \%$ leptomorph, as are the currently unplaced Vietnamocalamus and the two genera of hybrid origin $(\times$ Phyllosasa and Semiarundinaria). Clades I, II, III, VII, IX, XI and XII are 100\% pachymorph. Similarly, the 
percentage of the presence of pseudospikelets differed among the Shibataea (Clade IV), Phyllostachys (Clade V) and Arundinaria (Clade VI) clades. In the Shibataea clade (Clade IV), Shibataea is the only genus that possesses incomplete pseudospikelets, and the percentage of pseudospikelets at the genus and species levels are 33\% and 39\% respectively. Within the Phyllostachys clade (Clade V), Chimonobambusa and Phyllostachys are the two genera that have complete pseudospikelets and the percentages of pseudospikelets at the genus and species levels are $25 \%$ and $22 \%$ respectively. Within the Arundinaria clade (Clade VI), only Indosasa has complete pseudospikelets while Sinobambusa shows incomplete pseudospikelets or their inflorescences are unknown and the percentages of pseudospikelets at the genus and species levels are 20\% and 14\%. Even though some studies (Li et al., 2006) provide evidence for the presence of incomplete pseudospikelets for some Sinobambusa species, comprehensive morphological study is necessary to understand the reproductive structures in this genus. Otherwise, all of the other genera in Clade VI have conventional spikelets, as well as the members of Clades I, II, III, VII, VIII, IX, X, XI and XII and Vietnamocalamus. Both $\times$ Phyllosasa (=Hibanobambusa) and Semiarundinaria are of hybrid origin and possess entirely complete or incomplete pseudospikelets (100\%) (McClure 1966).

Of the outgroup taxa, Chusquea includes species with strictly pachymorph rhizomes or amphimorph rhizomes (both leptomorph and pachymorph morphologies present) or, in a very few cases, strictly leptomorph rhizomes, though our sampling included only a single species with pachymorph rhizomes. Of the 175 species of Chusquea, rhizome type is unknown for 39 (22\%), $119(68 \%)$ have pachymorph rhizomes and $17(10 \%)$ have leptomorph rhizomes, although only two are strictly leptomorph whereas the other 15 all have amphimorph rhizome systems. The two early-diverging lineages within Chusquea (subg. Magnifoliae and Platonia) are strictly 
pachymorph, rhizome condition is essentially undetermined for subg. Rettbergia, and the majority of the large Euchusquea clade (subg. Chusquea and subg. Swallenochloa) is pachymorph. The amphimorph and leptomorph taxa are clustered within sections Chusquea and Serpentes of subg. Chusquea, so even if subg. Rettbergia proves to be mainly amphimorph or leptomorph, the presence of leptomorph rhizomes in Chusquea is clearly derived. All species of Chusquea possess conventional spikelets (Clark et al. 2015).

The current study supports pachymorph rhizomes as the ancestral condition in Arundinarieae. Both Bambuseae and Olyreae are pachymorph (acknowledging that no species of Chusquea with amphimorph/leptomorph rhizomes were sampled) while Arundinarieae include both pachymorph and leptomorph taxa (Fig. 3A). Ampelocalamus calcareus clearly has pachymorph rhizomes, but within the remainder of the Arundinarieae, the situation is more complex and will require additional sampling to resolve. Leptomorph rhizomes originated once in the group comprising Clades VI, VIII and IV according to our sampling, and all bamboos classified in the genera assigned to these clades are leptomorph (Li et al., 2006). The clade comprising Clades III, XII, II and IX is uniformly pachymorph, both in our sampling and in all members otherwise assigned to these clades (Attigala et al., 2014). Likewise, Clade I + VII is strictly pachymorph across sampled and unsampled members. The ambiguity here stems from the position of Indocalamus sinicus, which is leptomorph, as part of a polytomy including Clade V and [(Clade III + Clade XII $)+($ Clade II + Clade IX) $]$, and the presence of both pachymorph and leptomorph taxa in the diverse Clade V, from which we sampled only two species (one pachymorph and one leptomorph). Hence, we tentatively conclude that pachymorph rhizomes are the ancestral condition in the evolutionary history of the Arundinarieae, and that leptomorph rhizomes either arose once with at least three reversions to the pachymorph condition (in Clade 
V, Clades III + XII + II + IX, and Clades I + VII) or leptomorph rhizomes arose independently at least two or three times (in Clades VI + IV + VIII, Clade V, and Indocalamus sinicus).

The character optimization of reproductive structures did not allow an unambiguous inference of the ancestral state in the Arundinarieae (Fig. 3B) due to the absence of known flowering material for Ampelocalamus calcareus. But based on the sampling analyzed here, we conclude that pseudospikelets evolved independently twice in the evolutionary history of Arundinarieae, regardless of the condition in Ampelocalamus calcareus. However, even though the taxa of the Arundinaria clade (Clade VI) that we sampled all have conventional spikelets, the presence of pseudospikelets is reported in Clade VI (Clayton et al., 2006 onwards; Li et al., 2006) and inclusion of those taxa in future analyses clearly would affect inferences regarding the evolution of reproductive structures in this tribe.

There is a potential explanation for the presence of incomplete pseudospikelets in Shibataea kumasaca of the Shibataea clade (Clade IV) that could be tested. Triplett and Clark (pers. comm.) speculate that the genus Shibataea may have an origin through hybridization, probably involving Phyllostachys, which was subsequently masked by introgression. Thus, the presence of incomplete pseudospikelets in Shibataea kumasaca could have been inherited from its progenitors, one of which (Phyllostachys) had pseudospikelets and one of which (a member of Clade IV) had conventional spikelets. Similarly, it is possible that the pseudospikelet morphologies observed in $\times$ Phyllosasa and Semiarundinaria may be derived from hybridization between one parent with a complete pseudospikelet and one parent with conventional spikelets. 


\section{Conclusions}

We investigated phylogenetic relationships of the 12 previously recognized lineages within tribe Arundinarieae of Bambusoideae using whole plastome sequence data and obtained a fully resolved phylogeny. Clade XI (Ampelocalamus calcareus) was strongly supported as sister to the remaining Arundinarieae, consistent with other recent analyses, and Clade XII (Kuruna), previously suggested as one of the potential early diverging lineages, was resolved as sister to Clade III (Chimonocalmus) with strong support. Competing alternative hypotheses suggested by different previous studies regarding relationships among the lineages of Arundinarieae were all shown to be less plausible when inferred from the plastome sequence matrix. Further, based on the analyses of morphological character evolution, we inferred that pachymorph rhizomes are the ancestral condition while leptomorph rhizomes either evolved once with reversions to the pachymorph condition or possibly multiple times within Arundinarieae. Pseudospikelets evolved independently a minimum of two times during the evolutionary history of Arundinarieae, but further analyses including more taxa from Clades V and VI are required to understand the origin and evolution of the different components of floral morphology.

The addition of plastomes from more taxa will likely provide additional insights into the evolutionary history of this economically and ecologically important tribe of woody bamboos, but plastomes provide only a maternally inherited signal. Previous studies have revealed complex relationships among Arundinarieae clades, with possible causes including intergeneric hybridization and reticulate evolution, rapid radiation, convergent evolution, and incomplete lineage sorting (Triplett and Clark 2010; Zeng et al. 2010; Zhang et al., 2012; Yang et al., 2013; Attigala et al., 2014; Ma et al., 2014; Triplett et al., 2014). We suggest that further studies utilizing bi-parentally inherited low-copy nuclear markers are needed to continue developing our 
understanding the complicated evolutionary history of the Arundinarieae, with particular emphasis on the impact of hybridization events.

\section{Acknowledgments}

This work was funded by National Science Foundation grants DEB-1120750 \& DEB0515712 to LGC and DEB-1120761 \& DEB-1342782 to MRD. This work was also partly supported by the Plant Molecular Biology Center, Northern Illinois University. The authors would like to thank Chris Pires, Dustin Mayfield and Patrick Edger for technical and laboratory assistance and access to laboratory facilities. Any opinions, findings, and conclusions or recommendations expressed in this material are those of the authors and do not necessarily reflect the views of the National Science Foundation.

\section{References}

Attigala, L., Triplett, J.K., Kathriarachchi, H.-S., Clark, L.G., 2014. A new genus and a major temperate bamboo lineage of the Arundinarieae (Poaceae: Bambusoideae) from Sri Lanka based on a multi-locus plastid phylogeny. Phytotaxa 174, 187-205. http://dx.doi.org/10.11646/phytotaxa.174.4.1.

Bamboo Phylogeny Group, 2005. Bamboo Biodiversity, Iowa State University. Available from <http://www.eeob.iastate.edu/research/bamboo/f> (Last accessed on: 06/06/2014).

Bamboo Phylogeny Group, 2012. An updated tribal and subtribal classification for the Bambusoideae (Poaceae), in: Gielis, J., Potters, G. (Eds.), Proceedings of the 9th World Bamboo Congress. Antwerp, Belgium, pp. 3-27.

Bergsten, J., 2005. A review of long-branch attraction. Cladistics 21, 163-193. http://dx.doi.org/10.1111/j.1096-0031.2005.00059.x. 
Burke, S.V., Clark, L.G., Triplett, J.K., Grennan, C.P., Duvall, M.R., 2014. Biogeography and phylogenomics of new world Bambusoideae (Poaceae), revisited. Am. J. Bot. 101, 886-891. http://dx.doi.org/10.3732/ajb.1400063.

Burke, S.V., Grennan, C.P., Duvall, M.R., 2012. Plastome sequences of two new world bamboos Arundinaria gigantea and Cryptochloa strictiflora (Poaceae) extended phylogenomic understanding of Bambusoideae. Am. J. Bot. 99, 1951-1961. http://dx.doi.org/10.3732/ajb.1200365.

Clark, L.G., Londoño, X., Ruiz-Sanchez, E., 2015. Bamboo taxonomy and habitat, in: Liese,W., Köhl, M. (Eds.), Bamboos, The plant and its uses. Springer International Publishing Switzerland, pp. 1-30.

Clayton, W.D., Vorontsova, M.S., Harman, K.T., Williamson, H., 2006 onwards. GrassBase The Online World Grass Flora. Available from < $\underline{\text { http://www.kew.org/data/grasses-db.html }>}$ (Last accessed on: 02 June 2015).

Cox, M.P., Peterson, D.A., Biggs, P.J., 2010. SolexaQA: At-a-glance quality assessment of illumina second-generation sequencing data. BMC Bioinform. 11, 485. http://dx.doi.org/10.1186/1471-2105-11-485.

Duvall, M.R, Leseberg, C.H., Grennan, C.P., Morris, L.M., 2010. Molecular evolution and phylogenetics of complete chloroplast genomes in Poaceae, in: Seberg, O., Petersen, G., Barfod, A.S., Davis, J.I. (Eds), Diversity, phylogeny, and evolution in the monocotyledons. Aarhus University Press, Aarhus, pp. 437-450. 
Graham, S.W., Olmstead, R.G., Barrett, S.C., 2002. Rooting phylogenetic trees with distant outgroups: a case study from the commelinoid monocots. Mol. Biol. Evol., 19, 1769-1781. http://mbe.oxfordjournals.org/content/19/10/1769.long.

Guindon, S., Gascuel, O., 2003. A simple, fast and accurate method to estimate large phylogenies by maximum-likelihood. Syst. Biol. 52, 696-704. http://dx.doi.org/10.1080/10635150390235520.

Holttum, R.E., 1956. The classification of bamboos. Phytomorphol. 6, 73-90.

Holttum, R.E., 1958. The bamboos of the Malay Peninsula. Gard. Bull. Singapore 16, 1-135.

Huelsenbeck, J.P., Ronquist, F., 2001. MRBAYES: Bayesian inference of phylogeny. Bioinform. $17,754-755$.

Huson, D.H., Bryant, D., 2006. Application of phylogenetic networks in evolutionary studies. Mol. Biol. Evol. 23, 254-267. http://dx.doi.org/10.1093/molbev/msj030.

Jansen, R.K., Cai, Z., Raubeson, L.A., Daniell, H., dePamphilis, C.W., Leebens-Mack J., MÜller K.F., Guisinger-Bellian, M., Haberle, R.C., Hansen, A.K., Chumley, T.W., Lee, S., Peery, R., McNeal, J.R., Kuehl, J.V., Boore, J.L., 2007. Analysis of 81 genes from 64 plastid genomes resolves relationships in angiosperms and identifies genome-scale evolutionary patterns. Proc.NatlAcad. Sci.U. S.A. 104, 19369-19374. http://www.pnas.org/content/104/49/19369.full.

Katoh, K., Kuma, K.I., Toh, H., Miyata, T., 2005. MAFFT version 5: improvement in accuracy of multiple sequence alignment. Nucleic Acids Res. 33, 511-518. http://dx.doi.org/10.1093/nar/gki198. 
Kelchner, S.A., Bamboo Phylogeny Group, 2013. Higher level phylogenetic relationships within the bamboos (Poaceae: Bambusoideae) based on five plastid markers. Mol. Phyl. Evol. 67, 404-413. http://dx.doi.org/10.1016/j.ympev.2013.02.005.

Kellogg, E.A. 2015. Volume XIII, Flowering Plants, Monocots, Poaceae, in: Kubitzki, K. (Ed.), The Families and Genera of Vascular Plants. Springer International Publishing, Switzerland, pp. 1-416.

Keng, P.C., 1982a. A revision of genera of bamboos from the world. I. J. Bamboo Res. 1, 1-19.

Keng, P.C., 1982b. A revision of genera of bamboos from the world. II. J. Bamboo Res. 1, 3146.

Keng, P.C., 1983a. A revision of genera of bamboos from the world. III. J. Bamboo Res. 2, 1127.

Keng, P.C., 1983b. A revision of genera of bamboos from the world. IV. J. Bamboo Res. 2, 117.

Keng, Y.L., 1959. Flora illustralis plantarum primarum sinicarum. Gramineae. Beijing Academia Sinica Press.

Li, D-Z., Wang, Z-P., Zhu, Z-D., Xia, N-H., Jia, L-Z., Guo, Z-H., Yang, G-Y., Stapleton, C., 2006. Bambuseae, in: Wu, Z-Y., Raven, P.H., Hong, D-Y. (Eds.), Flora of China: Poaceae, vol 22. Science Press, Missouri Botanical Garden Press, Beijing, St. Louis, pp. 7-180.

Lin, Y.H., McLenachan, P.A., Gore, A.R., Phillips, M.J., Ota, R., Hendy, M.D., Penny, D., 2002. Four new mitochondrial genomes and the increased stability of evolutionary trees of mammals from improved taxon sampling. Mol. Biol. Evol. 19, 2060-2070. http://mbe.oxfordjournals.org/content/19/12/2060.long. 
Ma, P.F., Zhang, Y.X., Zeng, C.X., Guo, Z.H., Li, D-Z., 2014. Chloroplast phylogenomic analyses resolve deep-level relationships of an intractable bamboo tribe Arundinarieae (Poaceae). Syst. Biol. 63, 933-950. http://dx.doi.org/10.1093/sysbio/syu054.

Maddison, W.P., Maddison, D.R., 2005. MacClade: analysis of phylogeny and character evolution, version 4.08. Sunderland, MA, USA: Sinauer Associates.

Maddison, W.P., Maddison, D.R., 2011. Mesquite: a modular system for evolutionary analysis. Version 2.75. Available from 〈http://mesquiteproject.org > (Last accessed on: 12 Jan 2015).

Mason-Gamer, R.J., Kellogg, E.A., 1996. Chloroplast DNA analysis of the monogenomic Triticeae: phylogenetic implications and genome specific markers, in: Jauhar, P.P., Raton, B. (Eds.), Methods of genome analysis in plants. CRC Press, pp. 301-325.

McClure, F.A., 1966. The bamboos: a fresh perspective. Harvard University, Press, Cambridge, Massachusetts, United States.

Moore, M.J., Soltis, P.S., Bell, C.D., Burleigh, J.G., Soltis, D.E., 2010. Phylogenetic analysis of 83 plastid genes further resolves the early diversification of eudicots. Proc. Natl. Acad. Sci. USA 107, 4623-4628. http://dx.doi.org/10.1073/pnas.0907801107.

NCBI Genbank, 2011. Available from <http://www.ncbi.nlm.nih.gov/genbank> (Last accessed on: 02 July 2014).

Parks, M., Cronn, R., Liston, A., 2009. Increasing phylogenetic resolution at low taxonomic levels using massively parallel sequencing of chloroplast genomes. BMC Biol. 7, 84 . http://www.biomedcentral.com/1741-7007/7/84.

Posada, D., 2008. jModelTest: phylogenetic model averaging. Mol. Bio. Evol. 25, 1253-1256. http://dx.doi.org/10.1093/molbev/msn083. 
Rivière, A., Rivière, C., 1879. Les Bambous (In French). Bulletin de la Societe d'Acclimatation 5, pp. 1-365.

Ronquist, F., Huelsenbeck, J. P., 2003. MRBAYES 3: Bayesian phylogenetic inference under mixed models. Bioinfor. 19, 1572-1574.

Ronquist, F., Huelsenbeck, J.P., Teslenko, M., 2011. MrBayes 3.2: Draft MrBayes version 3.2 Manual: Tutorials and model summaries. Available from $\langle$ http://mrbayes.sourceforge.net/mb3.2_manual.pdf $>$.

Shimodaira, H., Hasegawa, M., 1999. Multiple comparisons of log-likelihoods with applications to phylogenetic inference). Mol. Biol. Evol. 16, 1114-1116. http://mbe.oxfordjournals.org/content/16/8/1114.full.pdf.

Soderstrom, T.R., 1981. Some evolutionary trends in the Bambusoideae (Poaceae). Ann. Missouri Bot. Gard. 68, 15-47.

Soderstrom, T.R., Ellis, R.P., 1987. The position of bamboo genera and allies in a system of grass classification. in: Soderstom, T.R., Hilu, K.W., Campbell, C.S., Barkworth, M.E. (Eds.), Grass systematics and evolution. Smithsonian Institution Press. Washington, D.C. pp. 225-238.

Soderstrom, T.R., Ellis, R.P., 1988. The woody bamboos (Poaceae: Bambuseae) of Sri Lanka: a morphological-anatomical study. Smithsonian Contrib. Bot. 72, 1-75. http://dx.doi.org/10.5479/si.0081024x.72.

Soreng, R.J., Peterson, P.M., Romaschenko, K., Davidse, G., Zuloaga, F. O., Judziewicz, E.J., Filgueiras, T.S., Davis, J.I., Morrone, O., 2015. A worldwide phylogenetic classification of the Poaceae (Gramineae). J. Syst. Evol. 53, 117-137. 
Stamatakis, A., 2006. RAxML-VI-HPC: Maximum likelihood-based phylogenetic analyses with thousands of taxa and mixed models. Bioinform. 22, 2688-2690. http://dx.doi.org/10.1093/bioinformatics/btl446.

Stapleton, C.M.A., 1997. Morphology of woody bamboos, in: Chapman, G.P. (Ed.), The Bamboos. Academic Press, pp. 251-267.

Stapleton, C.M.A., 1994. The bamboos of Nepal and Bhutan part II: Arundinaria, Thamnocalamus, Borinda, and Yushania (Gramineae: Poaceae, Bambusoideae). Edinb. J. Bot. 51, 275-295.

Sullivan, J., Swofford, D.L., 1997. Are guinea pigs rodents? The importance of adequate models in molecular phylogenetics. J. Mamm. Evol. 4, 77-86. http://link.springer.com/article/10.1023\%2FA\%3A1027314112438

Swofford, D.L., 2002. PAUP*. Phylogenetic analysis using parsimony (*and other methods), version 4.0b10. Sunderland, MA, USA: Sinauer Associates.

Triplett, J.K., Clark, L.G., 2010. Phylogeny of the temperate bamboos (Poaceae: Bambusoideae: Bambuseae) with an emphasis on Arundinaria and allies. Syst. Bot. 35, 102-120. http://dx.doi.org/10.1600/036364410790862678.

Triplett, J.K., Clark, L.G., Fisher, A.E., Wen, J., 2014. Independent allopolyploidization events preceded speciation in the temperate and tropical woody bamboos. New Phytologist 204, 66-73. http://dx.doi.org/10.1111/nph.12988.

Tyrrell, C.D., Santos-Gonçalves, A.P., Londoño, X., Clark, L.G., 2012. Molecular phylogeny of the arthrostylidioid bamboos (Poaceae: Bambusoideae: Bambuseae: Arthrostylidiinae) and new genus Didymogonyx. Mol Phyl. Evol. 65, 136-148. 
Wen, T-H., 1985. Some ideas about the origin of bamboos. J. Amer. Bamboo Soc. 6, pp. 104111.

Wilcox, T.P., Zwickl, D.J., Heath, T.A., Hillis, D.M., 2002. Phylogenetic relationships of the dwarf boas and a comparison of Bayesian and bootstrap measures of phylogenetic support. Mol. Phyl. Evol. 25, 361-371.

Wolfe, A.D., Randle, C.P., 2004. Recombination, heteroplasmy, haplotype polymorphisam, and paralogy in plastid genes: implications for plant molecular systematics. Syst. Bot. 29, 10111020.

Wu, F.H., Kan, D.P., Lee, S.B., Daniell, H., Lee, Y.W., Lin, C.C., Lin, N.S., Lin, C.S., 2009. Complete nucleotide sequence of Dendrocalamus latiflorus and Bambusa oldhamii chloroplast genomes. Tree Physiol. 29, 847-856. http://dx.doi.org/10.1093/treephys/tpp015.

Wu, M., Lan, S., Cai, B., Chen, S., Chen, H., Zhou, S., 2015. The complete chloroplast genome of Guadua angustifolia and comparative analyses of Neotropical-Paleotropical bamboos. PLoS ONE 10, e0143792. http://dx.doi.org/10.1371/journal.pone.0143792.

Wu, Z.Q., Ge, S., 2012. The phylogeny of the BEP clade in grasses revisited: evidence from the whole-genome sequences of chloroplast. Mol. Phyl. Evol. 62, 573-578. http://dx.doi.org/10.1016/j.ympev.2011.10.019.

Wysocki, W.P., Clark, L.G., Attigala, L., Ruiz-Sanchez, E., Duvall, M.R., 2015. Evolution of the bamboos (Bambusoideae; Poaceae): a full plastome phylogenomic analysis. BMC Evol. Biol. 15, 50. http://dx.doi.org/10.1186/s12862-015-0321-5.

Wysocki, W.P., Clark, L.G., Kelchner, S.A., Burke, S.V., Pires, J.C., Edger, P.P., Mayfield, D.R., Triplett, J.K., Columbus, J.T., Ingram, A.L., Duvall, M.R., 2014. A multi-step 
comparison of short-read full plastome sequence assembly methods in grasses. Taxon 63 , 899-910. http://dx.doi.org/10.12705/634.5

Yang, H.M., Zhang, Y.X., Yang, J.B., Li, D.-Z., 2013. The monophyly of Chimonocalamus and conflicting gene trees in Arundinarieae (Poaceae: Bambusoideae) inferred from four plastid and two nuclear markers. Mol. Phyl. Evol. 68, 340-356.

http://dx.doi.org/10.1016/j.ympev.2013.04.002.

Zeng, C.X., Zhang, Y.X., Triplett, J.K., Yang, J.B., Li, D.-Z., 2010. Large multi-locus plastid phylogeny of the tribe Arundinarieae (Poaceae: Bambusoideae) reveals ten major lineages and low rate of molecular divergence. Mol. Phyl. Evol. 56, 821-839. http://dx.doi.org/10.1016/j.ympev.2010.03.041.

Zhang, W-P., 1992. The classification of Bambusoideae (Poaceae) in China. J .Am. Bamb. Soc. 9, 25-42.

Zhang, Y-J., Ma, P-F., Li, D.-Z., 2011. High-throughput sequencing of six bamboo chloroplast genomes: phylogenetic implications for temperate woody bamboos (Poaceae: Bambusoideae). PLoS One 6, e20596. http://dx.doi.org/10.1371/journal.pone.0020596.

Zhang, X-Z., Zeng, C-X., Ma, P-F., Haevermans, T., Zhang, Y-X., Zhang, L-N., Guo, Z-H., Li, D-Z., 2016. Multi-locus plastid phylogenetic biogeography supports the Asian hypothesis of the temperate woody bamboos (Poaceae: Bambusoideae). Mol. Phyl. Evol. 96, 118-129. 


\section{$\underline{\text { Figure Captions }}$}

Fig. 1. Bayesian inference (BI) phylogeny of Arundinarieae based on plastome sequences inferred from 28 taxa representing all 12 lineages of the tribe. Numbers indicate bootstrap values $\geq 70 \%$ from MP and ML analyses and posterior probabilities $\geq 0.95$ from the BI analyses, respectively. All values below these threshold support values were indicated with a "-." Roman numerals and the shadings associated with each clade represent the 12 different lineages of Arundinarieae.

Fig. 2. Neighbor-net analyses of Arundinarieae based on plastome data. Roman numerals represent the Arundinarieae clades. Arrows indicate the two sets of character conflicts seen in the plastome dataset.

Fig. 3. Morphological character evolution optimized onto the plastome phylogeny. A) Presence of leptomorph vs. pachymorph rhizomes and B) presence of conventional spikelets vs. pseudospikelets. 
Table 1. Specimen voucher information and GenBank accession numbers of plastome sequences. Shaded rows represent the newly assembled plastomes. All the vouchers are deposited at ISC unless otherwise indicated. Asterisks (*) denote the SSC and IR sizes that were estimated because of gapped regions. bp, base pairs; LSC, Large Single Copy Region; SSC, Short Single Copy Region; IR, Inverted Repeat Region.

\begin{tabular}{|c|c|c|c|c|c|c|c|c|}
\hline Species & Lineage & $\begin{array}{c}\text { GenBank } \\
\text { Accession } \\
\text { number } \\
\end{array}$ & ${ }^{\S}$ Voucher & $\begin{array}{l}\text { Genome } \\
\text { size (bp) }\end{array}$ & $\begin{array}{r}\text { LSC } \\
\text { (bp) }\end{array}$ & $\begin{array}{l}\text { SSC } \\
\text { (bp) }\end{array}$ & $\begin{array}{l}\text { IR } \\
(\mathbf{b p})\end{array}$ & $\begin{array}{l}\text { Missing } \\
\text { data }(\%)\end{array}$ \\
\hline Acidosasa purpurea (J.R. Xue \& T.P. Yi) Keng f. & VI & NC015820 & N/A & 139,697 & 83,273 & 12,834 & 21,795 & - \\
\hline Ampelocalamus calcareus C.D. Chu \& C.S. Chao & $\mathrm{XI}$ & KJ496369 & N/A & 139,689 & 86,580 & 13,305 & 22,049 & - \\
\hline Arundinaria appalachiana Triplett, Weakley \& L.G. Clark & VI & KC817462 & N/A & 139,547 & 83,222 & 12,717 & 21,804 & - \\
\hline Arundinaria gigantea (Walter) Muhl. & VI & JX235347 & N/A & 138,935 & 82,632 & 21,797 & 12,709 & - \\
\hline Arundinaria tecta (Walter) Muhl. & VI & KC817463 & N/A & 139,499 & 83,161 & 12,730 & 21,804 & - \\
\hline Bambusa bambos (L.) Voss & Bambusinae & KJ870988 & N/A & 142,772 & 79,972 & 12,868 & 24,966 & - \\
\hline Bergbambos tessellata (Nees) Stapleton & I & KU569967 & LC 1318 & 139,441 & 83,242 & 12,569 & 21,815 & - \\
\hline Chimonocalamus sp. & III & KU523577 & LC \& GR s.n. & 139,682 & 83,184 & 12,854 & 21,822 & - \\
\hline Chusquea spectabilis L.G. Clark & Chusqueinae & KJ870990 & N/A & 136,848 & 80,743 & 12,671 & 21,717 & - \\
\hline Cryptochloa strictiflora (E. Fourn.) Swallen & Olyrinae & JX235348 & N/A & 134,332 & 80,554 & 12,766 & 20,506 & 0.9 \\
\hline $\begin{array}{l}\text { Fargesia nitida (Mitford ex Anonymous) Keng f. ex T.P. Yi } \\
\text { (CAN) }\end{array}$ & $\mathrm{V}$ & KU569968 & JS 591531 & 139,559 & 83,158 & 12,807 & 21,797 & - \\
\hline Ferrocalamus rimosivaginus T.H. Wen & IV & HQ337794 & N/A & 139,467 & 83,091 & 12,718 & 21,829 & - \\
\hline $\begin{array}{l}\text { Gaoligongshania megalothyrsa (Hand.-Mazz.) D.Z. Li, J.R. Xue } \\
\& \text { N.H. Xia }\end{array}$ & IX & JX513419 & N/A & 140,064 & 86,580 & 13,305 & 22,049 & - \\
\hline Hordeum vulgare L. subsp. vulgare & Pooideae & NC008590 & N/A & 136,462 & 80,600 & 12,704 & 21,579 & - \\
\hline Indocalamus sinicus (Hance) Nakai & $\mathrm{X}$ & KJ531442 & N/A & 117,890 & 86,580 & 13,305 & 22,049 & 55.8 \\
\hline Indocalamus wilsonii (Rendle) C.S. Chao \& C.D. Chu & VIII & JX513421 & N/A & 139,962 & 86,580 & 13,305 & 22,049 & 0 \\
\hline Kuruna debilis (Thwaites) Attigala, Kathriar. \& L.G. Clark & XII & KU569969 & LA et al.123-5 & 118,047 & 82,878 & $* 15,143$ & $* 20,026$ & 8.3 \\
\hline Kuruna densifolia (Munro) Attigala, Kathriar. \& L.G. Clark & XII & KU569970 & LA et al.130-3 & 118,240 & 83,053 & $* 14,387$ & $* 20,800$ & 2.4 \\
\hline Lolium perenne L. & Pooideae & NC009950 & N/A & 135,246 & 80,000 & 12,428 & 21,409 & - \\
\hline Melocanna baccifera (Roxb.) Kurz & Melocanninae & KU569971 & XL \& LC 930 & 139,231 & 82,948 & 12,793 & 21,745 & 2.6 \\
\hline
\end{tabular}




\begin{tabular}{|c|c|c|c|c|c|c|c|c|}
\hline Species & Lineage & $\begin{array}{l}\text { GenBank } \\
\text { Accession } \\
\text { number }\end{array}$ & ${ }^{\S}$ Voucher & $\begin{array}{l}\text { Genome } \\
\text { size (bp) }\end{array}$ & $\begin{array}{r}\text { LSC } \\
\text { (bp) }\end{array}$ & $\begin{array}{l}\text { SSC } \\
\text { (bp) }\end{array}$ & $\begin{array}{c}\text { IR } \\
\text { (bp) }\end{array}$ & $\begin{array}{l}\text { Missing } \\
\text { data }(\%)\end{array}$ \\
\hline Oldeania alpina (K. Schum.) Stapleton & II & KU569972 & LA 170 & 139,602 & 83,206 & 12,762 & 21,817 & - \\
\hline Olmeca reflexa Soderstr. & Guaduinae & KJ870997 & N/A & 136,213 & 82,726 & 12,945 & 20,271 & - \\
\hline Olyra latifolia $\mathrm{L}$. & Olyrinae & KF515509 & N/A & 135,834 & 80,642 & 12,770 & 21,211 & - \\
\hline Phyllostachys aurea Carrière ex Rivière \& C. Rivière & $\mathrm{V}$ & KU569973 & LA 172 & 139,695 & 83,217 & 12,882 & 21,798 & - \\
\hline Pleioblastus hindsii (Munro) Nakai & VI & KU569974 & LC 1317 & 117,358 & 82,905 & 12,861 & 21,592 & 10.2 \\
\hline Sasa veitchii (Carrière) Rehder & VI & KU569975 & LC 1325 & 139,731 & 83,348 & 12,791 & 21,796 & - \\
\hline Shibataea kumasaca (Zoll. ex Steud.) Makino & IV & KU523578 & LC 1290 & 139,717 & 83,243 & 12,812 & 21,831 & - \\
\hline Thamnocalamus spathiflorus (Trin.) Munro & VII & KJ871005 & N/A & 139,498 & 83,310 & 12,594 & 21,797 & - \\
\hline
\end{tabular}

${ }^{\S}$ GR: Gary Reiners; JS: Jeff Saarela; LA: Lakshmi Attigala; LC: Lynn Clark; XL: Ximena Londoño. 
Table 2. Results of Shimodaira-Hasegawa (SH) test implemented in RAxML for the plastome dataset. D (LH) is the difference in log likelihood units between the best constrained tree and the best unconstrained tree. SD, Standard deviation.

\begin{tabular}{|c|c|c|c|c|}
\hline Topological constraints (Alternative hypotheses ) & *Likelihood & $\mathbf{D}(\mathbf{L H})$ & SD & $\begin{array}{c}\text { Significantly } \\
\text { worse }(p<0.01)\end{array}$ \\
\hline Clade V + Clade VII monophyletic & -242859.9545 & -746.8010 & 68.2463 & Yes \\
\hline Clade XII sister to the rest of the temperate woody bamboos & -242380.4997 & -267.3462 & 52.5368 & Yes \\
\hline Clade XII + Clade I monophyletic & -242827.5324 & -714.3790 & 65.7446 & Yes \\
\hline Clade XII + Clade VII monophyletic & -242835.4924 & -722.3390 & 65.1690 & Yes \\
\hline Clade I + Clade II monophyletic & -242869.7167 & -756.5633 & 67.6852 & Yes \\
\hline Clade XII + VII + I + II monophyletic & -242281.7698 & -168.6164 & 35.0310 & Yes \\
\hline
\end{tabular}

*Likelihood score of best plastome ML tree topology = -242113.1534. 
Table 3. Presence of different rhizome types and reproductive structures within Arundinarieae. Shaded rows represent the different clades and the asterisks $\left(^{*}\right)$ denote the genera included in the current study. Polyphyletic genera are indicated in bold and species of these genera belong to several clades within Arundinarieae. C, conventional spikelets; CP, complete pseudospikelets; IP, incomplete pseudospikelets; L, leptomorph rhizomes; P, pachymorph rhizomes.

\begin{tabular}{|c|c|c|c|c|c|c|c|c|}
\hline \multirow{3}{*}{$\begin{array}{l}\text { Genera within } \\
\text { Arundinarieae }\end{array}$} & \multirow{3}{*}{$\begin{array}{c}\text { No. of species in each } \\
\text { genus }\end{array}$} & \multirow{3}{*}{ Clade name } & \multicolumn{3}{|c|}{ Rhizomes } & \multicolumn{3}{|c|}{ Reproductive structures } \\
\hline & & & \multirow{2}{*}{ Type } & \multicolumn{2}{|c|}{ \% Leptomorph } & \multirow[t]{2}{*}{ Type } & \multicolumn{2}{|c|}{$\begin{array}{c}\% \text { Pseudospikelets } \\
\text { (Complete or Incomplete) }\end{array}$} \\
\hline & & & & Genera & Species & & Genera & Species \\
\hline Bergbambos* & 1 & I. Bergbambos & $\mathrm{P}$ & 0 & 0 & $\mathrm{C}$ & 0 & 0 \\
\hline Oldeania* & 1 & II. Oldeania & $\mathrm{P}$ & 0 & 0 & $\mathrm{C}$ & 0 & 0 \\
\hline Chimonocalamus* & 11 & III. Chimonocalamus & $\mathrm{P}$ & 0 & 0 & $\mathrm{C}$ & 0 & 0 \\
\hline Ampelocalamus* & 13 & $\begin{array}{l}\text { III. Chimonocalamus / } \\
\text { XI. Ampelocalamus calcareus }\end{array}$ & $\mathrm{P}$ & 0 & 0 & $\mathrm{C}$ & 0 & 0 \\
\hline Ferrocalamus* & 2 & IV. Shibataea & $\mathrm{L}$ & \multirow{3}{*}{100} & \multirow{3}{*}{100} & $\mathrm{C}$ & \multirow{3}{*}{33} & \multirow{3}{*}{39} \\
\hline Gelidocalamus & 9 & IV. Shibataea & $\mathrm{L}$ & & & $\mathrm{C}$ & & \\
\hline Shibataea* & 7 & IV. Shibataea & $\mathrm{L}$ & & & IP & & \\
\hline Bashania & 2 & V. Phyllostachys & $\mathrm{L}$ & \multirow{8}{*}{50} & \multirow{8}{*}{36} & $\mathrm{C}$ & \multirow{8}{*}{25} & \multirow{8}{*}{22} \\
\hline Chimonobambusa & 37 & V. Phyllostachys & $\mathrm{L}$ & & & $\mathrm{CP}$ & & \\
\hline Drepanostachyum & 10 & V. Phyllostachys & $\mathrm{P}$ & & & $\mathrm{C}$ & & \\
\hline Fargesia* & 90 & V. Phyllostachys & $\mathrm{P}$ & & & $\mathrm{C}$ & & \\
\hline Himalayacalamus & 8 & V. Phyllostachys & $\mathrm{P}$ & & & $\mathrm{C}$ & & \\
\hline Phyllostachys* & 51 & V. Phyllostachys & $\mathrm{L}$ & & & $\mathrm{CP}$ & & \\
\hline Sarocalamus & 3 & V. Phyllostachys & $\mathrm{L}$ & & & $\mathrm{C}$ & & \\
\hline Yushania & 80 & V. Phyllostachys & $\mathrm{P}$ & & & $\mathrm{C}$ & & \\
\hline
\end{tabular}




\begin{tabular}{|c|c|c|c|c|c|c|c|c|}
\hline \multirow{3}{*}{$\begin{array}{l}\text { Genera within } \\
\text { Arundinarieae }\end{array}$} & \multirow{3}{*}{$\begin{array}{l}\text { No. of species in each } \\
\text { genus }\end{array}$} & \multirow{3}{*}{ Clade name } & \multicolumn{3}{|c|}{ Rhizomes } & \multicolumn{3}{|c|}{ Reproductive structures } \\
\hline & & & \multirow[t]{2}{*}{ Type } & \multicolumn{2}{|c|}{ \% Leptomorph } & \multirow[t]{2}{*}{ Type } & \multicolumn{2}{|c|}{$\begin{array}{c}\% \text { Pseudospikelets } \\
\text { (Complete or Incomplete) }\end{array}$} \\
\hline & & & & Genera & Species & & Genera & Species \\
\hline Acidosasa* & 11 & VI. Arundinaria & $\mathrm{L}$ & & & $\mathrm{C}$ & & \\
\hline Arundinaria* & $\begin{array}{l}3 \text { (+ ca. } 6 \text { of uncertain } \\
\text { placement })\end{array}$ & VI. Arundinaria & $\mathrm{L}$ & & & $\mathrm{C}$ & & \\
\hline Indosasa & 15 & VI. Arundinaria & $\mathrm{L}$ & & & $\mathrm{CP}$ & & \\
\hline Oligostachyum & 15 & VI. Arundinaria & $\mathrm{L}$ & & & $\mathrm{C}$ & & \\
\hline Pleioblastus* & 40 & VI. Arundinaria & $\mathrm{L}$ & 100 & 100 & $\mathrm{C}$ & 20 & 14 \\
\hline Pseudosasa & 19 & VI. Arundinaria & $\mathrm{L}$ & & & $\mathrm{C}$ & & \\
\hline Sasa* & 40 & VI. Arundinaria & $\mathrm{L}$ & & & $\mathrm{C}$ & & \\
\hline Sasaella & 13 & VI. Arundinaria & $\mathrm{L}$ & & & $\mathrm{C}$ & & \\
\hline Sasamorpha & 5 & VI. Arundinaria & $\mathrm{L}$ & & & $\mathrm{C}$ & & \\
\hline Sinobambusa & 10 & VI. Arundinaria & $\mathrm{L}$ & & & IP & & \\
\hline Thamnocalamus* & 3 & VII. Thamnocalamus & $\mathrm{P}$ & 0 & 0 & $\mathrm{C}$ & 0 & 0 \\
\hline Gaoligongshania* & 1 & IX. Gaoligongshania & $\mathrm{P}$ & 0 & 0 & $\mathrm{C}$ & 0 & 0 \\
\hline Indocalamus* & 23 & $\begin{array}{l}\text { IV. Shibataea / } \\
\text { V. Phyllostachys / } \\
\text { VIII. Indocalamus wilsonii / } \\
\text { X. Indocalamus sinicus }\end{array}$ & $\mathrm{L}$ & 100 & 100 & $\mathrm{C}$ & 0 & 0 \\
\hline Kuruna* & 7 & XII. Kuruna & $\mathrm{P}$ & 0 & 0 & $\mathrm{C}$ & 0 & 0 \\
\hline Vietnamocalamus & 1 & Incertae Sedis & $\mathrm{L}$ & 100 & 100 & $\mathrm{C}$ & 0 & 0 \\
\hline $\begin{array}{l}\times \text { Phyllosasa } \\
(=\text { Hibanobambusa })\end{array}$ & 1 & Hybrid origin & $\mathrm{L}$ & 100 & 100 & $\begin{array}{l}\mathrm{CP} \text { or } \\
\mathrm{IP}\end{array}$ & 100 & 100 \\
\hline Semiarundinaria & 10 & Hybrid origin & $\mathrm{L}$ & 100 & 100 & $\mathrm{CP}$ & 100 & 100 \\
\hline
\end{tabular}




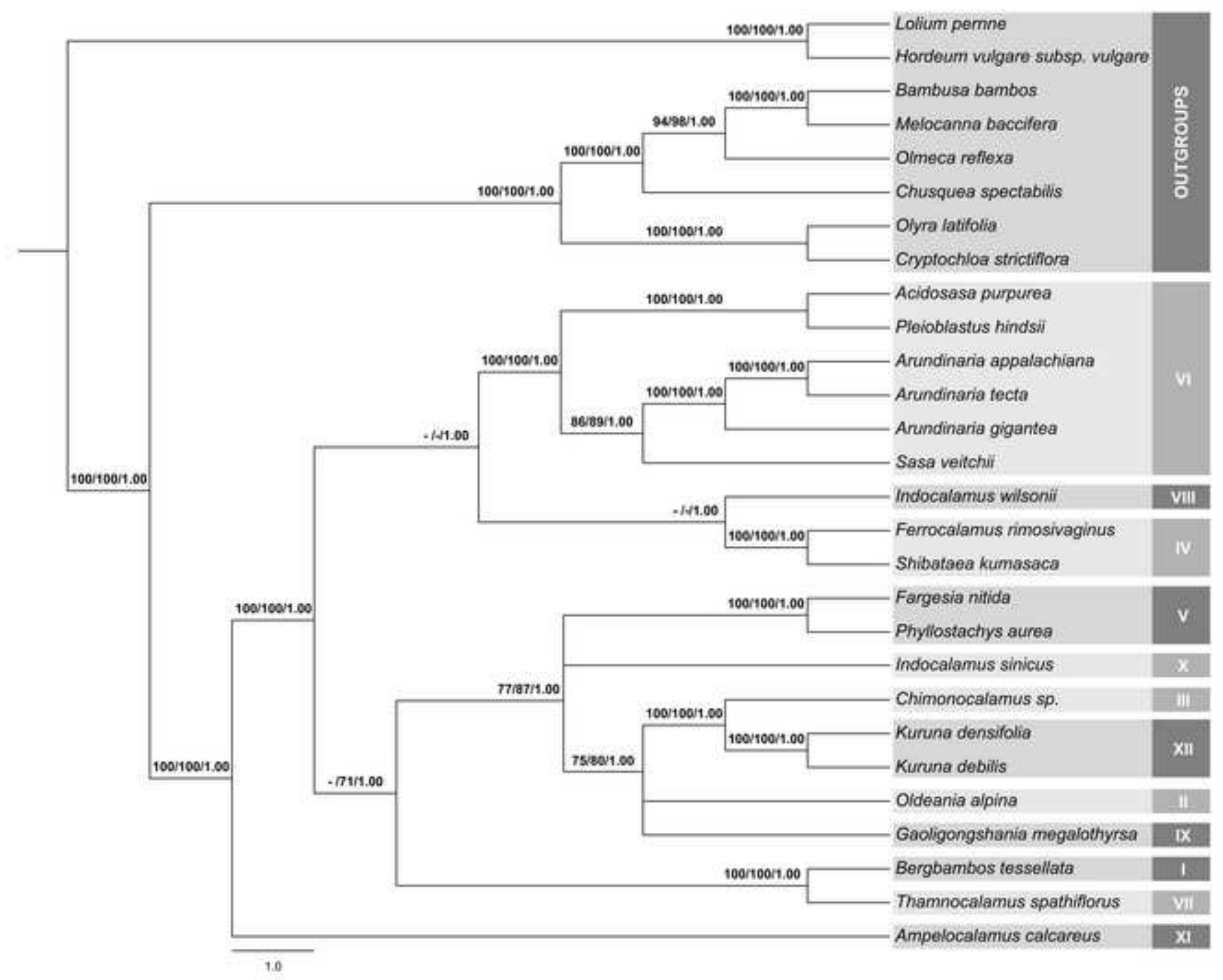




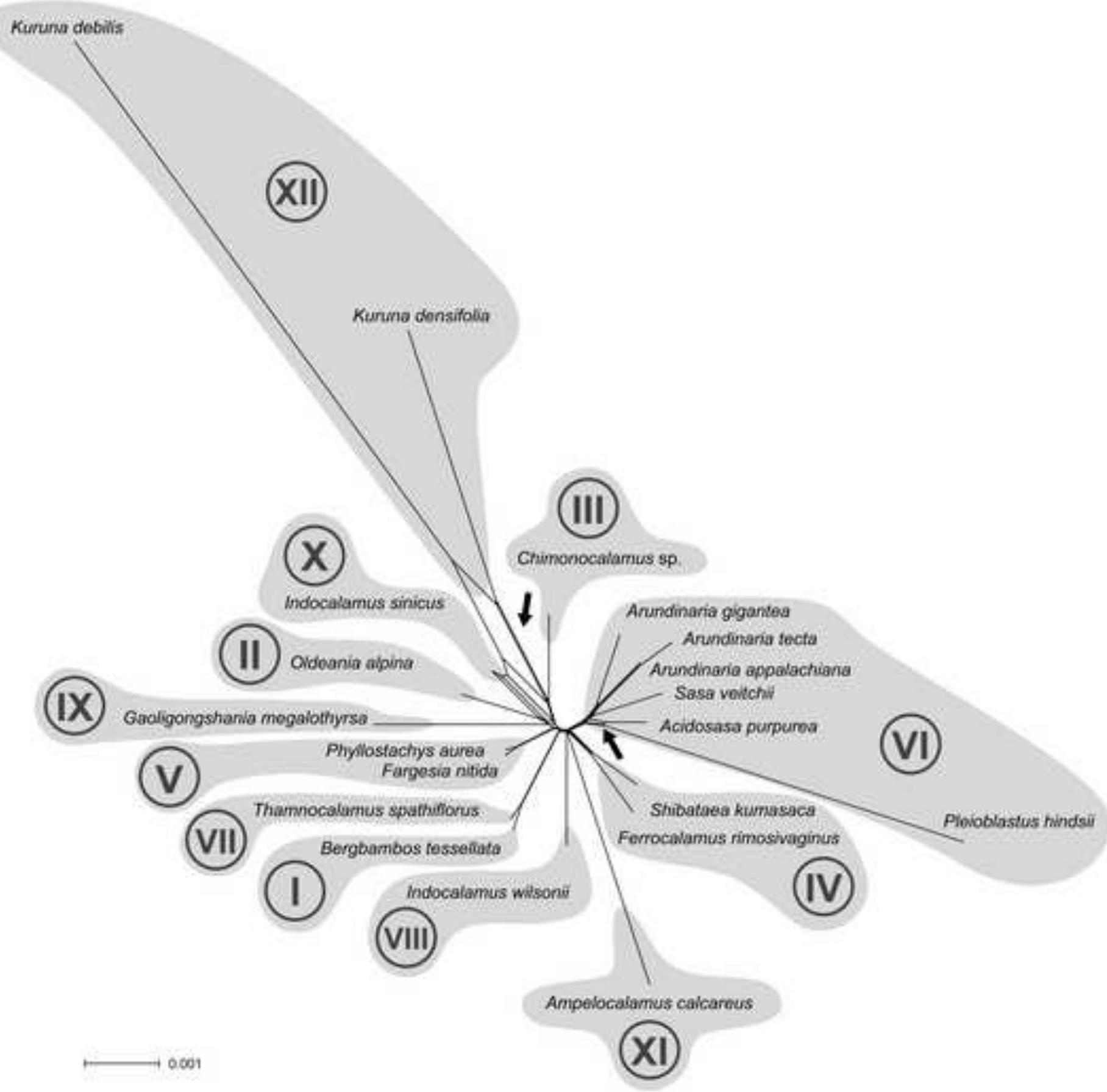


A

Hordeum vulgare subsp. vulgare

\begin{tabular}{|c|}
\hline Lolium perenne \\
\hline Cryptochloa strictiflora \\
\hline Olyra Jatifolia \\
\hline Chusquea spectabilis \\
\hline Olmeca reflexa \\
\hline
\end{tabular}

Bambusa bambos

Melocanna baccifera

Ampelocalamus calcareus

Bergbambos tesseliata

Thamnocalomes spathiflorus

\section{Oldeania ofpina}

Gaoligongshania megalothyrsa

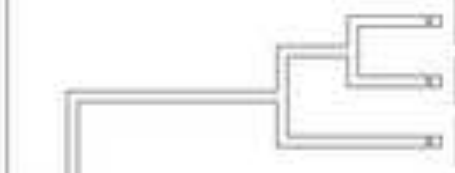

$\frac{1}{9}$

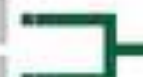

\section{Rhizomes}

$\square$ Leptomorph thizomes

- Pachymorph thizomes

II Character not applicable
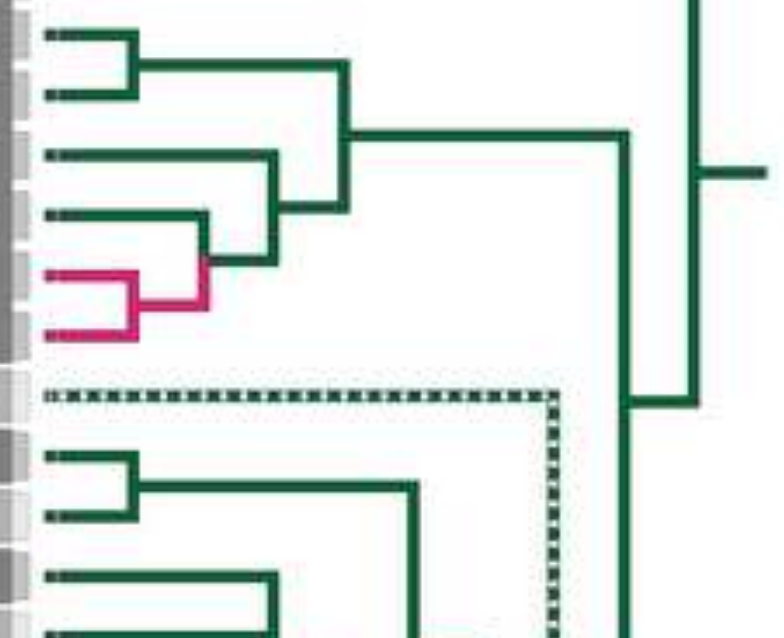

Kuruna debilis

Kuruna densifolia

indocolamus sinicus

Fargesia nitida

Phyllostachys aurea

Shibatoea kumasace

Ferrocalamus rimosivaginus

III

xi!

V

I

Indocalamus wilsonii

Acidosasa purpurea Pleioblastus hindsii

Sasa veitchi

Arundinaria gigantea

Arundinaria appalachiana Arundinaria tecta
VI$$
\text { fin }
$$
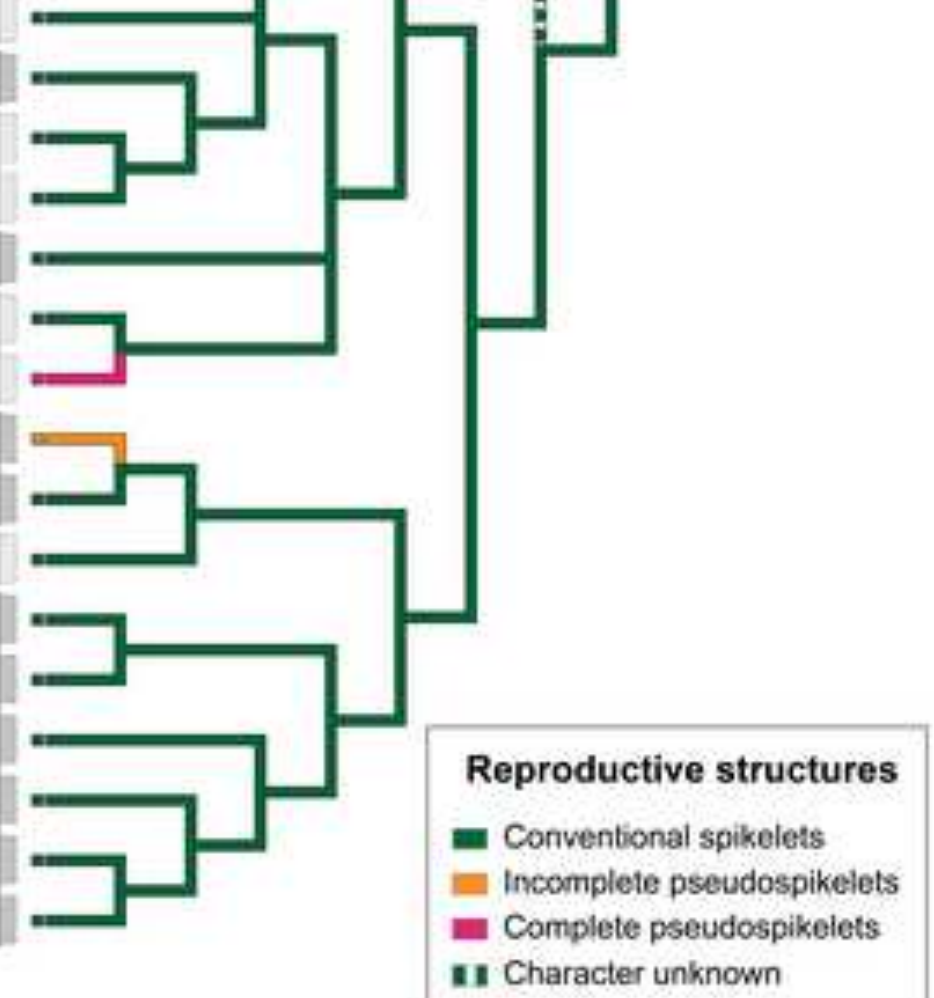


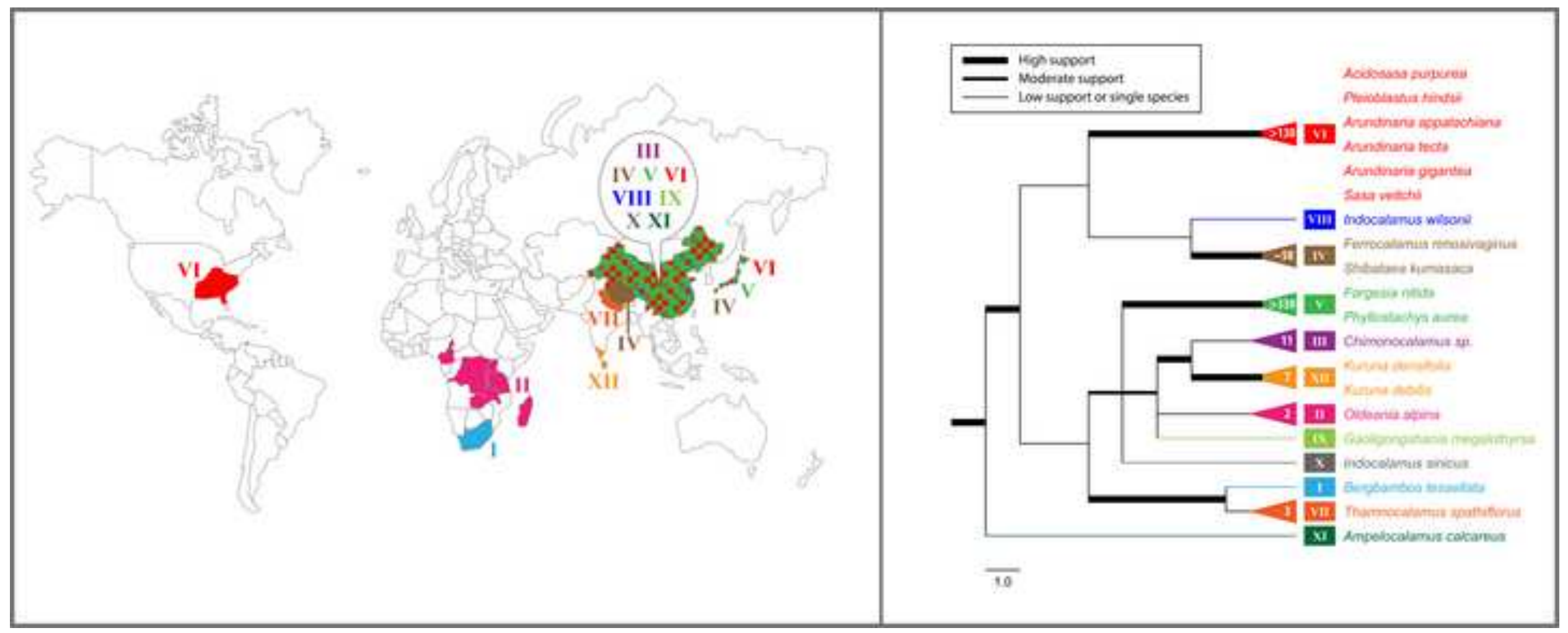

